\title{
Assessing Capacity and Performance of Health Systems Using Principal Component Analysis: Results from Cross Sectional Survey in Kakamega County, Western Kenya
}

\author{
Maximila N. Wanzala ${ }^{1} \quad$ Vincent Were $^{2^{*}} \quad$ J.A Oloo $^{1} \quad$ Gordon Nguka ${ }^{1}$ \\ 1. Masinde Muliro University of Science and Technology, Department of Public health, Kakamega, Kenya \\ 2. Kenya Medical Research Institute, Centre for Global Health Research, Kisumu, Kenya
}

\begin{abstract}
Background: Strong health systems are fundamental if countries are to improve health outcomes and accelerate the attainment of the Sustainable Development Goal (SDGs) number 3 'Ensure healthy lives and promote wellbeing for all at all ages.' Despite the strong consensus on need to strengthen health systems, many health systems lack the capacity to measure or understand their own weakness and constraints which effectively leaves policy makers without ideas of what they should actually strengthen.

Methods: Principal Component Analysis (PCA) was used to factor weights which were used to assess individual contribution of indicators to the health system performance. PCA is a type of a multivariable linear regression of all indicators in one model. PCA index was classify variables from heighted to the lowest indicator and further used to rank the indicator. Indicators of individual health system building block were weighted independently to measure the amount of contribution to the respective health system building block. The weights were then aggregated to produce individual health system building block indices which were the independent variables in the multivariable linear regression model. Coefficients of the regression was used to assess marginal effects and p-value $<0.05$ were considered statistics significant result

Results: Service delivery $(p<0.0001)$, health financing $(p<0.0001)$, health workforce $(p=0.005)$ and medical supplies and commodities $(\mathrm{p}<0.0001)$ had significant effect on service provision. Health governance was not a significant factor influencing service provision.

Conclusions: Among the health system building blocks that significantly influenced service provision were service delivery, health workforce, and health financing and medical supplies. This is the first study to the best of the knowledge of the researcher to apply principal component analysis, to analyze health system performance in a devolved system Kakamega. The method provides opportunity for future application in health systems analysis even in absence of comparative data
\end{abstract}

Keywords: Principal Component Analysis, Health Systems

DOI: $10.7176 / \mathrm{JHMN} / 59-03$

\section{Background}

Strong health systems are fundamental if countries are to improve health outcomes and accelerate the attainment of the Sustainable Development Goal (SDGs) number 3 'Ensure healthy lives and promote well-being for all at all ages.' Despite the strong consensus on need to strengthen health systems, many health systems lack the capacity to measure or understand their own weakness and constraints which effectively leaves policy makers without ideas of what they should actually strengthen([1]. Health service provision is vital in any given health system. Health workforce, procurement, supplies and financing are essential for effective service provision Health is crucial for attaining the sustainable development goals (SDGs), and it's also a measure of the progress of a nation towards achieving sustainable development. To date, Kenya continues to grapple with numerous challenging health problems and issues in the delivery of accessible, affordable and equitable health services despite efforts to improve the health system by devolution. The decentralization of the government since 2013 gave rise to the county government system which currently governs the health systems. Ever since the onset of county government, counties continue to pay salaries for health workers. However, some amount of control on the human resource remained with the National government. These make the counties unable to manage the health workers adequately due to limited information on their discipline, training needs, promotions, and retirement. Health worker supervision has led to delayed salaries and, in some cases, health worker strikes due to such disputes. The national $\mathrm{MOH}$ has also been slow to restructure. Without an adequate political will, it is unlikely that MOH headquarters staff will be reassigned to assist County Health Management Teams (CHMTs) or provide health services as originally envisioned [2].

Devolution of health care in Kenya since the enactment of the new constitution in 2010 and 2013 national election was aimed at ensuring health care was more improved, more efficient and available for all citizens at affordable cost. It was envisioned that health services would be timely delivered and closely minored for proper utilization of health service resources. However, inadequacies in the health system continue to be reported with challenges still existing centralized government regime despite devolution of health services. 
Kakamega county happens to be among those counties that have the worst health indicators Maternal mortality in Kakamega county is at 880/100000 live births almost doubling the national figure of 448/100000 live birth that is much higher than WHO acceptable range of $92 / 100000$ live births. The neonatal mortality is equally high in the county at 28/1000 live births way above the national estimate of below 27/1000[3].

According to a government policy note there are inefficiencies in resource distribution at the national level. They are claimed to have lead towards the current poor working conditions at county level including the health workers' salary payment delay.

Kenya Health Policy 2014-2030 [4] had laid emphasis on resource allocation based on technical and allocative efficiency. However, since the inception of devolved system, there is little published evidence of performance of health indicators especially using advanced analytical methods such as principal component analysis to monitor progress towards achieving the SGD 3 in Kakamega County.

The purpose of the study is to determine the effect of devolve system of government of the capacity of the Kakamega County Health systems to provide efficient service delivery. contribution and potential to contribute to the county government on six health system building blocks; service delivery, Medical supplies, health financing, health workforce and health leadership and governance in Kenya towards achieving the Sustainable Development Goals (SDGs).

For the sustainable development goals (SDGs) to be achieved, one of the key components is to ensure that the health system is effectively managed in any existing government. SDG 3 happens to integrate the others and none of the SDGs can operate independently. In Kenya, county governments came into being with the March 2013 elections. It is three years since devolution, but the quality of health care is still insufficient. Since devolution of the health system in Kenya, there is poor understanding regarding available capacities in regards to system-wide capacity due to lack of proper regulation of institutional, technical and Community capacities. Quantification of the essential health system capacity is crucial for the county government's planning and even advisory to the policy makers towards achieving the SDGs.

Our paper aims to use to measure the strength of health systems in Kakamega County using Principal component analysis method (PCA). Principal Component Analysis generates an index/factor weights for each health system indicator. The factor weights can then be used to rank and assess the contribution of each indicator in the overall health system provision[5].The weight is a measure of how much an indicator contributes to the health service provision. The study aimed to demonstrate the association of the health system indicators and the indices and also uses of the indices on measuring and also monitoring the strength of the health system.

\section{Methods}

\section{Ethics statement}

The study involved interviews with health facility managers from various departments after obtained of oral and informed consent. The participants rights were protected as stated in the informed consent, the consent also state clearly that participants were free to ask questions. The participants were informed that their names will not be published. Confidentiality was assured and anonymity taken care of as the names of the participants are not used in the report.

Ethical clearance was obtained from Masinde Muliro University of Science and Technology Ethics Committee and National science and Technology Research Review board.

\section{Consent statement}

Data from each health facility was collected from the facility in-charge and the most knowledgeable person. Verbal informed consent was obtained from the facility in-charge. Each facility in-charge was read an explanation pertaining the study aims, confidentiality and privacy. The facilities were selected according to probability proportional to the number of facility type and no individual's name would be recorded. The respondents were informed that participation was voluntary and that information they provided would be further used to address concerns to the county government and also used as evidence in policy making. Verbal consent, if provided was noted on the questionnaire as well as the respondent's signature.

\section{Indicators and variables}

Indicators were adopted from the Kenya Service Availability and Readiness Mapping (SARAM) report[6]. A subset of 231 of the indicators were selected to represent the six building blocks of health system which comprise of service delivery indicators, health workforce indicators, health financing indicators, information systems, health governance indicators and medical and supplies indicators. The identification of the 231 indicators was based on a clinical review of the variables in the SARAM report that would be accessible as checklist if our results were to be used for routine monitoring. 


\section{The statistical procedure}

Quantitative data was analyzed suing descriptive statistics and using principal component analysis (PCA) which is a factor analysis regression model. PCA is a mathematical procedure which transforms a number of (possibly) correlated variables into a (smaller) number of uncorrelated variables called principal components. PCA is useful with a number of variables which are believed to be correlated. In mathematical terms, from an initial set of $n$ correlated variables, PCA creates uncorrelated indices or components called Principal Components (PC). A PC is a linear combination of variables such that the coefficients on each variable maximize the variance of that PC [7]. The model as shown below $\mathrm{PC}_{1}=\mathrm{a}_{11} \mathrm{x}_{1}+\mathrm{a}_{12} \mathrm{x}_{2}+\mathrm{a}_{13} \mathrm{x}_{3}+\ldots \ldots . .+\mathrm{a}_{1 \mathrm{n}} \mathrm{x}_{\mathrm{n}}$

Where $P C_{i}$ is principal component $i$; $a_{i k}$ represents the weight for the $k^{\text {th }}$ variable for the $i^{\text {th }}$ principal component. Technically, a principal component can be defined as a linear combination of optimally-weighted observed variables. PCs are extracted in decreasing order of importance so that the first PC accounts for as much of the variation as possible hence $\mathrm{PC}_{1}$ selected. PCA generates PCA loadings (weights) which are the measure of importance of each indicator in accounting for the variability in the principal component.

To determine the contribution of the national health systems policy on devolved service delivery, health workforce, medical supplies and commodities, health financing and health governance indicators were included in the PCA model. PCA generated an index/weight for each indicator. This weight was a measure of contribution of an indicator to health service provision which was used to fit a multiple linear regression as the dependent variable. Also, PCA generated a principal component for each health facility. The principal component is the total of the weights of all health system indicators available in a facility. The principal component which is also the facility weights were used to generate 3 clusters (quintiles) which grouped the health facilities into best performing, medium performing and poor performing health facilities. Cluster three had facilities with overall high weight, cluster two had facilities with medium weights and cluster one had facilities with overall high weight. Hence cluster 3 was composed of the good performing health facilities while cluster 1 was composed of the poorly performing health facilities.

\begin{tabular}{ccc}
\hline Table 1: Fraction of health facilities in each quintile. & Percent \\
Quintiles & n & 33.80 \\
2 & 24 & 33.80 \\
3 & 24 & 33.29 \\
\hline
\end{tabular}

Facility weights were used to assess performance of sub counties. Facility weights of facilities within each subcounty were aggregated and used to rank sub counties in Kakamega County. Also, Indicators of individual health system building block were weighted independently to measure the amount of contribution an indicator contributes to the respective health system building block. The weights were then aggregated to produce individual health system building block index which were the independent variables in a regression model.

\section{Results}

The study was conducted in 71 health facilities across Kakamega County which included five County referral hospitals (7.04\%), seven sub-county Hospitals (9.86\%), 57 health centers $(80.28 \%)$, one nursing home and one mission hospital. Majority of the facilities $(6 / 71,95.77 \%)$ were public facilities and most $(88.73 \%)$ of them were located in the rural of Kakamega County. A total of 34 health facilities provided outpatient services. The health facilities were distributed across all the 8 sub counties in Kakamega County. 


\begin{tabular}{|c|c|c|}
\hline Characteristics & $n=71$ & Percent (\%) \\
\hline \multicolumn{3}{|l|}{ Type of facility } \\
\hline County Referral Hospitals & 5 & 7.04 \\
\hline Sub-County Hospitals & 7 & 9.86 \\
\hline Health Centers & 57 & 80.28 \\
\hline Maternity/Nursing Home & 1 & 1.41 \\
\hline Mission Hospital & 1 & 1.41 \\
\hline \multicolumn{3}{|l|}{ Managing Authority } \\
\hline Government/public & 68 & 95.77 \\
\hline Mission/Faith based & 3 & 4.23 \\
\hline \multicolumn{3}{|l|}{ Location } \\
\hline Rural & 63 & 88.73 \\
\hline Urban & 8 & 11.27 \\
\hline \multicolumn{3}{|l|}{ Outpatient services only } \\
\hline Yes & 34 & 47.89 \\
\hline No & 37 & 52.11 \\
\hline \multicolumn{3}{|l|}{ Sub counties } \\
\hline Lugari sub county & 6 & 8.45 \\
\hline Lurambi sub county & 5 & 9.86 \\
\hline Malava sub county & 8 & 11.27 \\
\hline Shinyalu sub county & 7 & 9.86 \\
\hline Butere sub county & 8 & 11.27 \\
\hline Mumias East sub county & 3 & 4.23 \\
\hline Likuyani sub county & 6 & 8.45 \\
\hline Navakholo sub county & 7 & 9.86 \\
\hline Khwisero sub county & 5 & 7.04 \\
\hline Matungu sub county & 7 & 9.86 \\
\hline Ikolomani sub county & 7 & 9.86 \\
\hline
\end{tabular}

Performance of health service provision in Kakamega County

Ranking of health service provision indicators

From table 3 below, Functioning microscope had the highest weight $(0.1492)$ hence contributed a high weight in the overall service provision followed by (Routine inpatient care) in that order. Availability of malaria rapid diagnostic kit indicator had the least weight (-0.0928). All the top five indicators were service delivery indicators.

\begin{tabular}{|c|c|c|c|c|}
\hline Rank & Service delivery indicators $\mathrm{N}=71$ facilities & $\begin{array}{l}\text { (N)Number of } \\
\text { facilities }\end{array}$ & percent & Weights \\
\hline 1 & Availability of functioning microscope & 45 & 63.38 & 0.1477 \\
\hline 1 & This facility routinely have in-patient care & 33 & 46.48 & 0.1477 \\
\hline 3 & Availability of Giesma or field stain & 47 & 66.20 & 0.1459 \\
\hline 4 & $\begin{array}{l}\text { Providers in the facility diagnose and/or manage } \\
\text { diabetes in patients }\end{array}$ & 34 & 47.89 & 0.1452 \\
\hline 5 & Availability of microscope (for malaria smear test) & 54 & 76.06 & 0.1448 \\
\hline 6 & Availability of Dipstick or urine protein & 45 & 63.38 & 0.1441 \\
\hline 7 & Availability of Dipstick or urine glucose & 44 & 61.97 & 0.1402 \\
\hline 8 & Availability of Dipstick or urine ketones & 47 & 66.2 & 0.1380 \\
\hline 9 & This facility has a functioning computer & 34 & 47.89 & 0.1370 \\
\hline 10 & Medical male ward & 26 & 36.62 & 0.1368 \\
\hline
\end{tabular}

\section{Last 10 service delivery indicators}

Dependency on rain water, public tap, unprotected springs and wells as the main source of water were among the low in ranking. This is because most of the facilities had water piped into the facility and boreholes (ranked 50 and 89 in appendix 4) as the main sources of water. Malaria rapid diagnostic test was ranked low as opposed to malaria smear tests (ranked 85 in appendix 4). Having a functioning landline telephone had a low factor score since it is an outdated technology replaced by mobile phones (ranked 76 in appendix 4). Availability of a pit latrine with a slab had a low factor score since a ventilated improved pit latrine (ranked 88 in appendix 4) is the most recommended type of toilet facility. 
Table 1: Least ranked service delivery indicators.

\begin{tabular}{|l|l|l|l|l|}
\hline Rank & Service delivery indicators & $\mathbf{n}$ & percent & Weights \\
\hline 107 & $\begin{array}{l}\text { This facility has a functioning landline telephone that is available } \\
\text { to call outside at all times that client services are offered? }\end{array}$ & 4 & 5.63 & -0.0277 \\
\hline 108 & $\begin{array}{l}\text { Unprotected spring as the most commonly used source of water } \\
\text { in the facility }\end{array}$ & 2 & 2.82 & -0.0300 \\
\hline 109 & $\begin{array}{l}\text { Unprotected well as the most commonly used source of water in } \\
\text { the facility }\end{array}$ & 2 & 2.82 & -0.0303 \\
\hline 110 & $\begin{array}{l}\text { Public tap/standpipe as the most commonly used source of water } \\
\text { in the facility }\end{array}$ & 2 & 2.82 & -0.0366 \\
\hline 111 & Pit latrine with slab as the type of toilet & 31 & 43.66 & -0.0456 \\
\hline 112 & $\begin{array}{l}\text { Rooms with both auditory and visual privacy available for patient } \\
\text { consultations }\end{array}$ & 44 & 61.97 & -0.0462 \\
\hline 113 & Auto-disable needle and syringes & 5 & 7.04 & -0.0507 \\
\hline 114 & Functioning Malaria rapid diagnostic kit & 64 & 90.14 & -0.0686 \\
\hline 115 & Availability of malaria rapid diagnostic kit & 65 & 91.55 & -0.0907 \\
\hline 116 & $\begin{array}{l}\text { Rainwater collection as the most commonly used source of water } \\
\text { in the facility }\end{array}$ & 10 & 14.08 & -0.1013 \\
\hline
\end{tabular}

\section{Performance of health system building blocks}

Figure1 shows that among the health system building blocks in this study, service delivery had the highest mean weight (2.68 E-08). Service delivery was the best performing health system building block compared to the rest. Health workforce was second with a mean of 1.77E-08. Health financing was third with a mean of $1.60 \mathrm{E}-08$ and Medical products vaccines \& technologies came in fourth in ranking with a mean of $1.13 \mathrm{E}-08$. Service delivery, health workforce, medical supplies and health financing had positive impact while Leadership and governance had a negative contribution to health service provision. It had a mean of $-3.57 \mathrm{E}-09$.

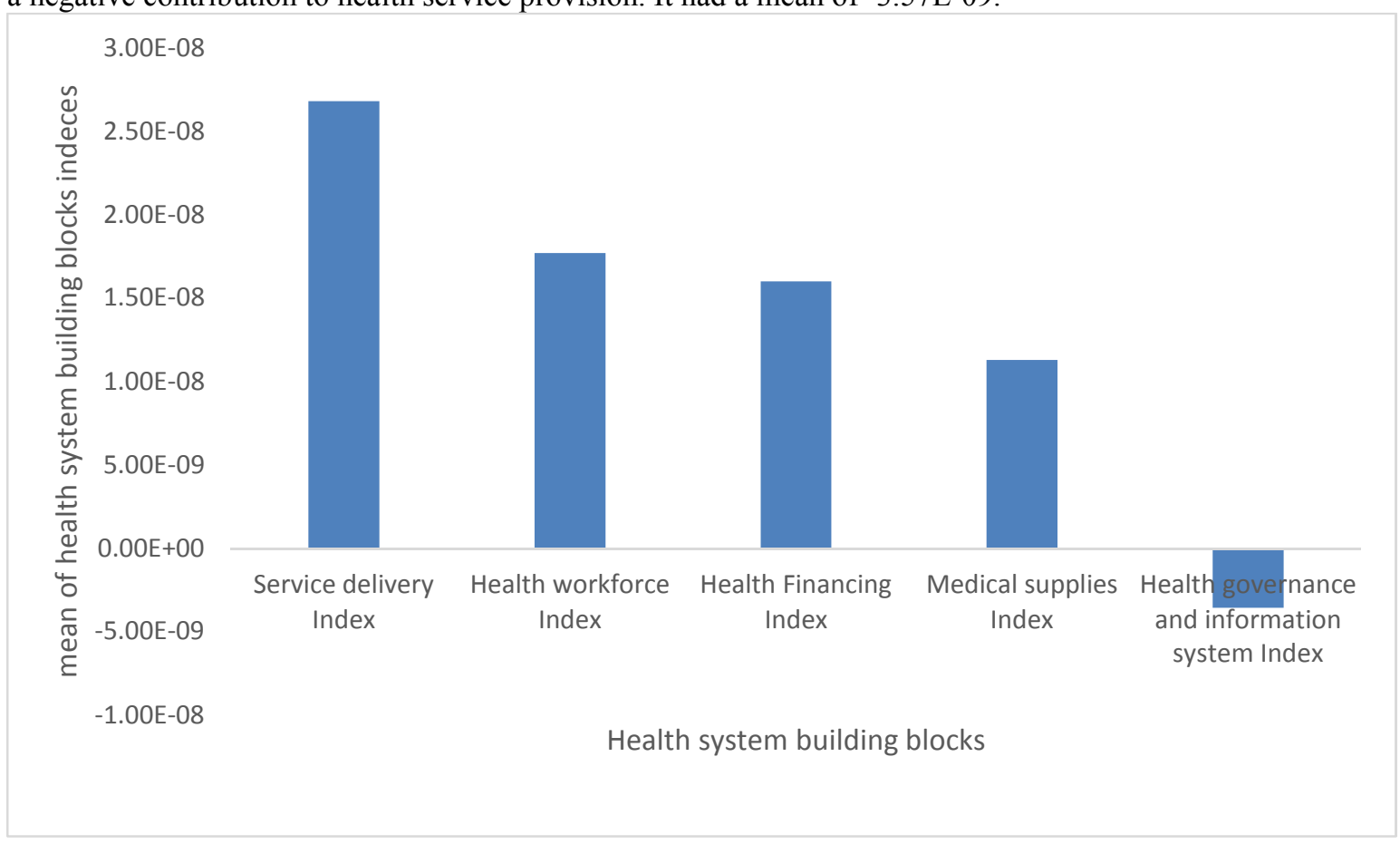

Figure 1 Mean of health system building blocks.

Influence of health system building blocks on service provision

To study the influence of the Service delivery, Health workforce, health financing, medical supplies and health governance on the overall factor weight of the indicators in all indicators in the whole of Kakamega County, a regression model was fitted. Results of the regression analysis shown in table 6 reveal that Service delivery $(\mathrm{p}<0.0001)$, health financing $(\mathrm{p}<0.0001)$, health workforce $(\mathrm{p}=0.005)$ and medical supplies and commodities $(\mathrm{p}<0.0001)$ had significant effect on service provision in Kakamega county. Health governance was not a significant factor influencing service provision. 
Table 4: Effect of health system building blocks' indices on health service provision.

\section{Indices of Health system building blocks}

Service delivery

Health Governance and information systems

Medical supplies and Commodities Health Workforce

Health Finance

\section{Regression} coefficient

0.95
95\% Confidence Interval

0.93-0.97

$-0.08-0.02$

0.33-0.40

$0.02-0.11$

$0.01-0.11$

The outcome was health service provision index

$\begin{array}{ccc}0.36 & 0.33-0.40 & * \\ 0.06 & 0.02-0.11 & 0.005^{*} \\ 0.06 & 0.01-0.11 & 0.017 *\end{array}$

$\mathrm{R}^{2}=99.62$

\section{Discussion}

The study has established that health service delivery was the best performing health system building block compared to the rest in a devolved governance system in Kakamega County. Service delivery influenced health service provision positively. In the multivariate regression analysis assessing the impact of all building blocks of health service provision, servicer delivery has a positive impact index and statistically significant in health service provision. Kakamega County has been leading in investment in health care and also in delivery of health care. According a recent report by the county government on its performance compared to other counties in the country. Kakamega County came up with a programme called "Oparanya care" dubbed "Afya ya mama na mtoto" which pays or gives a pregnant woman incentive to deliver in an health facility. The programme aimed to reduce the high infant and maternal mortality rate in the county [8]. Women who are financially handicapped are enrolled and are enabled to access health care using out-of-pocket payments. As a result there has been progress to deliver efficient, cost effective and equitable health services. This current results may be a reflection of the efforts on service delivery.

Health governance and information systems was the worst ranked pillars of health system under a devolved governance structure in Kakamega County. It generated an overall negative ranking index compared to other building blocks. This findings of this study are comparable to a qualitative study conducted in Kilifi county of Kenya which established that political persuasion influenced the rush to devolve health function faster than was anticipated by most sector players [9]. The authors concluded that while implementation of the devolved government system in Kenya significantly increased the decision making space for human resource of health (HRH) and Essential Medicines and Medical Supplies (EMMS) management, county governments lacked capacity to do certain tasks [9]. This study has demonstrated that while there is positive improvement is ensuring community health units are functional, this has not translated in availability of accurate data that can be relied upon to make priority decisions. Accurate data is essential tool for decision making and this has greatly underperformed in the developed system in Kakamega County.

Health Policy Project (HPP), partnered with Kenya ministry of medical Services (MOMS) and the Ministry of Public Health and Sanitation MOPHS on developing a common understanding of the structures, opportunities, and challenges of devolution for health sector actors. The partnership facilitated the ministries of health understand how devolution would divide authority and responsibility between the national and county governments, as outlined in the 2010 constitution and subsequent relevant legislation. It was from this forum that the health managers recognized the need to prepare better for these significant systemic changes by proposing definitions for national and county-level functions[10].

In the regression analysis assessing how the governance, leadership and information system has been affected, the overall regression coefficient was negative but non-significant. This would imply that the health information system has been negatively affected since devolved governance. The lack of significance also implied that there was no improvement and may reflect lack of progress to provide timely, accurate data for decision making within the county.

Health personnel was second best rated after service delivery indicating significant increase under devolved governance. The regression model showed that human resources had a positive coefficient and was significantly associating with increased service provision in a devolved system. Health financing index had a positive and statistically significant coefficient implying that health financing significantly improved under devolved system of governance which was in contrast with a study conducted in Kenya on effect of devolution on health care delivery in Nakuru county which revealed that health care financing deteriorated after devolution [11]. Similarly, a study on challenges of the devolved health care services in Kenya also revealed that health financing is still a challenge in health care even after decentralization [12]. The findings of this study therefore shows there has been improvement in increasing financial resources from the national to devolved units. County government also have 
found new funding streams to suppliant the national funds. Among the indicators that were rated, use of NHIF in the facilities had the highest positive factor weight implying that use of NHIF in the facilities significantly impacted positively service provision after devolution. The national insurance fund like any other insurance may have made it feasible to finance several services both for the users and service providers.

The other indicator with positive effect was the main source of financial support. If the county government provided the funds, there is direct sufficient effect on service provision in a devolved governance. This contrasts a study which found out that there was an overlap of role of national government and county government in delivery of service in health and this has led to conflict in service delivery which has affected contribution of county government[13]. Moreover, a study on devolution and its effects on health workforce and commodity management in Kilifi county revealed that there was also lack of clarity over specific roles and responsibilities at county and national government, and of key players at each level hence affecting the contribution of the county government in the service provision[9].

However, the indicators least ranked were whether facilities received financial support from the national government for health care delivery since devolved system of government and national government as the main source of financial support. This showed that, whether facilities received financial support from the national government or the national government as the main source of financial support in the health facilities least impacted service provision on decentralization. This is because of allocations from the national Ministry of Finance are often delayed or may have stringent conditions for use. This is merely speculative and may need further research. This concurs with a study in Meru county on influence of devolution of government service delivery on provision of health care which revealed that national government was the major source of financing but the finances were not received on time hence contributing least to service delivery after decentralization [14].

The study has several strengths and limitations. The key strength of this paper is that it have applied up to 155 indicators of the health system using a PCA model to reduce the factors to the building blocks and provides the first attempt to policy makers to assess performance of the health systems. This is the first study to assess performance of the health system indicators using PCA under a devolved governance. The main limitation of this paper are that they was lack of a comparison of data before and after he developed functions. This may have showed which indicators have improved and which one have declined. However, the application of factor weights provides an option in absence of a comparison data. The findings of this study is only generalizable to Kakamega County and not nationally but the methods can be replicated nationally. Lastly this was a cross sectional study which lacks ability to monitor effect of time and has several confounding factors the analysis has not address which can be improved in future research

\section{Conclusions}

This study established that service delivery was the best performing health system building block compared to health workforce, health financing, health governance and medical supplies in a devolved government environment. Health workforce was second, health financing was third, medical supplies was fourth and health governance was least performing. The five health system indicators with the highest factor weight were; availability of a functioning microscope for malaria smear test, routine inpatient care, availability of giesma or field stain for malaria smear test, diagnosis and management of diabetes and availability of a microscope for malaria smear test. All these were service delivery indicators.

On medical supplies and commodities, Insulin injection had the highest impact factor followed by metformin cap/tab then ACE inhibitor. For health financing, use of NHIF card had the highest factor weight followed by county as the main source of finance then donor as the main source of finance. The highest factor weight among health governance/information was adequate summary forms for data collection followed by accurate and reliable data for the CHMTs to develop strategic plans. For health workforce, Clinical officers assigned in the facility had the highest factor weight followed by nursing professionals then specialist medical doctors/ consultants part time in a facility.

Among the health system building blocks that significantly influenced service provision were service delivery, health workforce, and health financing and medical supplies.

This is the first study to the best of the knowledge of the researcher to apply principal component analysis, inferential statistical analysis, to analyze health system performance in a devolved system Kakamega. The method provides opportunity for future application in health systems analysis even in absence of comparative data

\section{Recommendations of the study}

The study has established that under a devolved county governance in Kenya, there has been marked improvement in service delivery compared to health workforce, health financing. This implies that the number of health workforce and financing has also increased significantly. The government should strengthen legislation on use on efficient employment policy to avoid blotted works force. The increased availability of funding to counting government should be sustained and bottlenecks removed to ensure counties are in charge of funds. Health 
governance and data quality performed the poorest and this underscore the low interest the county governance has for health related data. While there was $100 \%$ meeting attendance by health committees, such meeting do not seem to address governance challenges including health information management system and data utilizations for policy decision. Revision of policies and by-laws should be enhance to ensure policies are based on data

Continuous assessment of impact of components of health systems under devolution is required to the inform enhancement of health service provision in the county. Stakeholder should continuous engage to address the poor performance sectors.

A future study should conduct a quasi-experimentation study to compare data between counties, with a baseline and endline periods. This would improve of cross sectional survey design. Another recommendation

\title{
Declarations \\ Ethics Approval
}

Ethical clearance was obtained from Masinde Muliro University of Science and Technology Ethics Committee (Re: MMU/COR: 403009(50). Consent and approval was also obtained from Kakamega county director of heath (Ref: CGK/MOH/OCo/1/120) CHMT Chair of the identified health facilities and the local administration in each of the sub counties. The respondents were the health facility mangers who provided informed consent on behalf the health facilities

\begin{abstract}
Abbreviations
SDGs; Sustainable development goals; (SARAM) Kenya Service Availability and Readiness Mapping; CHMTs; County health management teams; GOK: Government of Kenya; IRB: institutional review board; KEMRI: Kenya Medical Research Institute; PCA: Principal Component analysis; MOH: Ministry of Health; WHO: World Health Organization.
\end{abstract}

\section{Competing interest}

The authors declare that they have no competing interests.

\section{Authors' contributions}

MW and DN conceived, designed, coordinated and performed the study. MW and VW analyzed the data. MW, VW, JO, DN drafted manuscript. All authors read and approved the final manuscript.

\section{Disclaimer}

The findings and conclusions presented in this manuscript are those of the authors and do not necessarily reflect the official position of Masinde Muliro University and KEMRI

\section{Acknowledgements}

We are grateful to the health facilities which granted permission to participate in this study, the county government of Kakamega and the facility managers

\section{Data Sharing}

Requests for the data used for this analyses may be made to lead author, Vincent Were, vwere@kemricdc.org and can be shared

\section{Funding}

This was a self-sponsored by the lead author who is a PhD student at Masinde Muliro University

\section{REFERENCES}

1. De Savigny, D. and T. Adam, Systems thinking for health systems strengthening. 2009: World Health Organization.

2. Williamson, T. and A. Mulaki, Devolution of Kenya's health system, the role of HPP. RTI International, 2015.

3. Demographic, K., Health Survey 2014: key indicators. Kenya National Bureau of Statistics (KNBS) and ICF Macro, 2014.

4. Health, M.o., Kenya Health Policy 2014-2030. 2014, Ministry of Health Nairobi, Kenya.

5. Kolenikov, S. and G. Angeles, The use of discrete data in principal component analysis for socio-economic status evaluation. Carolina, NC: University of North Carolina at Chapel Hill, 2005.

6. Kenya, G.o., Kenya Service Availability and Readiness Assessment Mapping (SARAM). 2014, Ministry of Health Nairobi.

7. Scharadin, B.P., Principal component analysis of state level food system Indicators. 2012.

8. Kimani, L. and G.S. Namusonge, FACTORS INSTRUMENTAL TO SUSTAINABILITY OF PROJECTS IN 
KENYA: A CASE STUDY OF OPARANYA MOTHER CARE KAKAMEGA COUNTY. Strategic Journal of Business \& Change Management, 2016. 3(4).

9. Tsofa, B., et al., How does decentralisation affect health sector planning and financial management? a case study of early effects of devolution in Kilifi County, Kenya. International journal for equity in health, 2017. 16(1): p. 151.

10. HPP, HEALTH POLICY PROJECT/KENYA Building capacity for improved health policy,advocacy, governance, and finance. . 2014.

11. Koikai, J.S., An Evaluation of the Effects of Devolution on Healthcare Delivery in Nakuru County. 2015.

12. AWINO, O.E., RESPONSE STRATEGIES ADOPTED BY THE MINISTRY OF HEALTH TO CHALLENGES OF DEVOLVED HEALTHCARE SERVICES IN KENYA. 2016, SCHOOL OF BUSINESS, UNIVERSITY OF NAIROBI.

13. Wambua, K.C. and Z. Kiruthu, Decentralization of Government Operations and Service Delivery Performance by County Governments in Kenya. Master's Thesis, University of Nairobi, School of Business, Nairobi, Kenya, 2014.

14. Miriti, A.K. and P. Keiyoro, Influence of devolution of government service delivery on provision of healthcare: A case of level five hospital in Meru County, Kenya. International Academic Journal of Information Sciences and Project Management, 2017. 2(1): p. 316-334. 